\title{
Disruption studies of a Candida albicans gene, ELF1: a member of the ATP-binding cassette family
}

\author{
Joy Sturtevant, Ronald Cihlar and Richard Calderone
}

Department of Microbiology \&

Immunology, Georgetown University School of

Medicine, Washington DC 20007, USA
Author for correspondence: Joy Sturtevant. Tel: +1 202687 1801. Fax: +1 2026871800.
e-mail: jstury01@medlib.iaims.georgetown.edu

Keywords: Candida albicans, ATP-binding cassette gene, gene disruption

\section{INTRODUCTION}

Candida albicans is the most prevalent opportunistic fungal pathogen and is one of the major aetiological agents of nosocomial infections (Matthews, 1994). The clinical importance of candidiasis has increased recently due to the onset of AIDS and medical procedures including immunosuppressive therapy and organ transplants. Since $C$. albicans avidly binds to mucosal surfaces and catheters (Hawser \& Douglas, 1994), this normally benign organism can rapidly become invasive in immunosuppressed patients. The mortality rate in systemic candidiasis is high $(38-59 \%)$, due in part to difficulties in diagnosis and treatment (Matthews, 1994). Since yeasts are eukaryotic, many antifungal agents are also toxic to host cells. The azoles, a group of antifungal compounds, are effective against mucocutaneous infections but development of resistance in chronically infected patients is high (Sangeorzan et al., 1994; Pfaller et al., 1994; McCullogh \& Hume, 1995). In one study, all strains isolated from patients developed resistance to

Abbreviations: $A B C$, ATP-binding cassette; FOA, 5-fluoroorotic acid; MDR, multidrug resistance; $P S K+, p B l u e s c r i p t ~ S K+$

The GenBank accession number for the sequence reported in this paper is AF038153. fluconazole, clotrimazole and itraconazole but not ketoconozole (McCullogh \& Hume, 1995). Additionally, the high recurrence of oropharyngeal candidiasis in HIV-positive patients did not always correspond with increased azole resistance (Pfaller et al., 1994). Consequently, there is an important need to identify new antifungal targets and develop new treatment strategies.

The ATP-binding cassette (ABC) transporter proteins are of interest because of their association with a drugresistance phenotype and because they are potential antifungal target proteins. The genes encoding $A B C$ proteins share significant sequence homology, including a conserved amino acid domain of approximately $200 \mathrm{bp}$ which is associated with ATP binding. Many of the ABC proteins consist of two homologous halves with a nucleotide-binding-fold domain and six predicted membrane-spanning regions per half. Their known functions include the transport of small molecules or proteins bidirectionally across membranes, such as the efflux of cytotoxic compounds (reviewed by Higgins, 1992). Members of the ABC family include multi-drug resistance (MDR) proteins from tumour (Pglycoprotein) and bacterial cells. Overexpression of the P-glycoprotein, and consequently an ATP-dependent extrusion pump, increases the resistance of cancer cells to cytotoxic drugs (Gottesman \& Pastan, 1993). Genes 
conferring similar phenotypes have been reported for Saccharomyces cerevisiae (SNQ2 and PDR5) and C. albicans (CDR1) (reviewed by Balzi \& Goffeau, 1994) and CDR2 (Sanglard et al., 1997). In addition to genes encoding the MDR proteins, genes involved in translation are also members of the ABC gene family. GCN20 from $S$. cerevisiae, for example, is a positive effector of GCN2, and, thus, is indirectly involved in activation of translation initiation factor 2 (Vazquez de Aldana et al., 1995). GCN20 shows significant sequence similarities to genes that encode elongation factor 3 (EF-3). EF-3 genes are found in several fungi including $C$. albicans (Colthurst et al., 1992), Pneumocystis carinii (YpmaWong et al., 1992) and S. cerevisiae (Qin et al., 1990). The EF-3 proteins are attractive antifungal targets since they are not found in mammalian cells, but are essential for translation in fungal cells.

In this paper, we describe the identification and gene disruption of a new member of the ABC gene family in C. albicans, ELF1. Sequence analysis (Devereux et al., 1984) identified two putative nucleotide-binding domains and an $A B C$ transporter consensus sequence. Although the sequence of the $S$. cerevisiae homologue, ORF YPL226W, has been reported, no function or phenotype has yet been determined. Therefore, it is of interest to study this gene to determine whether it may play a role in drug resistance or growth of the organism.

\section{METHODS}

Strains and culture conditions. The C. albicans strains used in this study are listed in Table 1 . Strains SC5314, CAF2-1 and CAI4 were donated by William Fonzi (Georgetown University). Strains were maintained on YPD medium (Sherman et al., 1986) at $30^{\circ} \mathrm{C}$. Minimal medium (YNB) contained yeast nitrogen base with $0.5 \%(\mathrm{w} / \mathrm{v})$ ammonium sulfate supplemented with $2 \%(\mathrm{w} / \mathrm{v})$ dextrose. When required, $25 \mu \mathrm{g}$ uridine $\mathrm{ml}^{-1}$ was added. Ura ${ }^{-}$auxotrophs were selected on YNB supplemented with $1 \mathrm{mg} 5$-fluoroorotic acid $\mathrm{ml}^{-1}$ (FOA; Boeke et al., 1984).
The yeast-to-hyphal transition was induced by either culture media or serum (Shepherd et al., 1980). Tissue culture medium (M199) or $2.5 \%$ foetal calf serum was inoculated with 5-10 $\times$ $10^{5}$ cells ml ${ }^{-1}$ from an overnight culture and incubated rocking at $37^{\circ} \mathrm{C}$ for $30 \mathrm{~min}$ to $2 \mathrm{~h}$. Germ-tube formation was monitored by light microscopy.

The growth rates of heterozygote and homozygote disrupted strains were compared with the parental or the URA3 heterozygote strain, CAF2-1. Strains were grown overnight in YPD at $30^{\circ} \mathrm{C}$. Equivalent numbers of yeast cells were inoculated into YPD or YNB so that the starting $\mathrm{OD}_{550}$ of a 1:10 dilution was 0.03 (approx. $10^{6}$ cells). The OD was measured at $1 \mathrm{~h}$ intervals for $9 \mathrm{~h}$ in three separate experiments. Cells were also counted manually using an Improved Neubauer haemocytometer.

DNA manipulations and transformations. Plasmid isolation and enzymic reactions were performed either by standard methods (Sambrook et al., 1989) or according to the manufacturer's instructions. Bacterial transformations were performed using Escherichia coli DH5 $\alpha$ competent cells prepared in calcium chloride or by electroporation with E. coli XL1Blue cells (Bio-Rad E. coli pulser; manufacturer's directions). C. albicans was transformed by lithium acetate following the protocol of Gietz et al. (1992). Selection of Ura ${ }^{+}$transformants and FOA segregants was performed as described by Fonzi $\&$ Irwin (1993). Genomic DNA was isolated from C. albicans spheroplasts (Philippsen et al., 1991) using Zymolyase-20T (ICN Biomedicals). An EcoRI SC5314 genomic library was constructed in Lambda Zap II following the manufacturer's instructions (Stratagene).

Isolation of ELF1. A C. albicans 4918 genomic DNA library constructed in $\lambda$ gt11 was screened using non-formamide hybridization conditions (Sambrook et al., 1989) at $55^{\circ} \mathrm{C}$ with $\lambda \mathrm{E} 41$, the clone of the human $\mathrm{B}$ cell $\mathrm{C} 3 \mathrm{~d}$ receptor gene (Moore et al., 1987). Library screening and phage purification were performed by routine methods (Titus, 1991). Positive plaques were purified and a $3 \cdot 2 \mathrm{~kb} E c o R I$ fragment was isolated which hybridized with $\lambda E 41$ (Calderone et al., 1992). The 5' EcoRI fragment was isolated by screening the Lambda Zap II library with pABC-4, a plasmid derived by inverse PCR (see below).

Table 1. C. albicans strains used in this study

\begin{tabular}{|c|c|c|c|}
\hline Strain & $\begin{array}{l}\text { Parental } \\
\text { strain }\end{array}$ & Relevant genotype & Source/reference \\
\hline 4918 & & ELF1/ELF1 URA3/URA3 & Manning \& Mitchell (1980) \\
\hline SC5314 & & ELF1/ELF1 URA3/URA3 & Gillum (1984) \\
\hline CAF2-1 & SC5314 & ELF1/ELF1 $\triangle u r a 3 / U R A 3$ & Fonzi \& Irwin (1993) \\
\hline CAI4 & CAF2-1 & ELF1/ELF1 $\triangle u r a 3 / \Delta u r a 3$ & Fonzi \& Irwin (1993) \\
\hline CAJS1 & CAI4 & 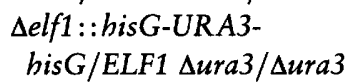 & This work \\
\hline CAJS2 & CAI4 & 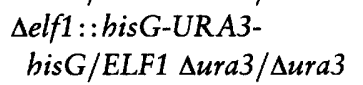 & This work \\
\hline CAJS1E & CAJS1 & 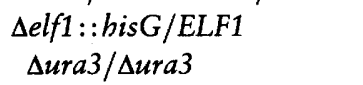 & This work \\
\hline CAJS2D & CAJS2 & $\begin{array}{l}\Delta e l f 1:: \text { hisG/ELF1 } \\
\text { Aura } 3 / \Delta u r a 3\end{array}$ & This work \\
\hline CAJS5 & CAJS2D & 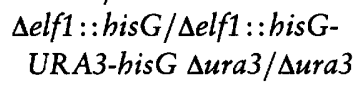 & This work \\
\hline
\end{tabular}




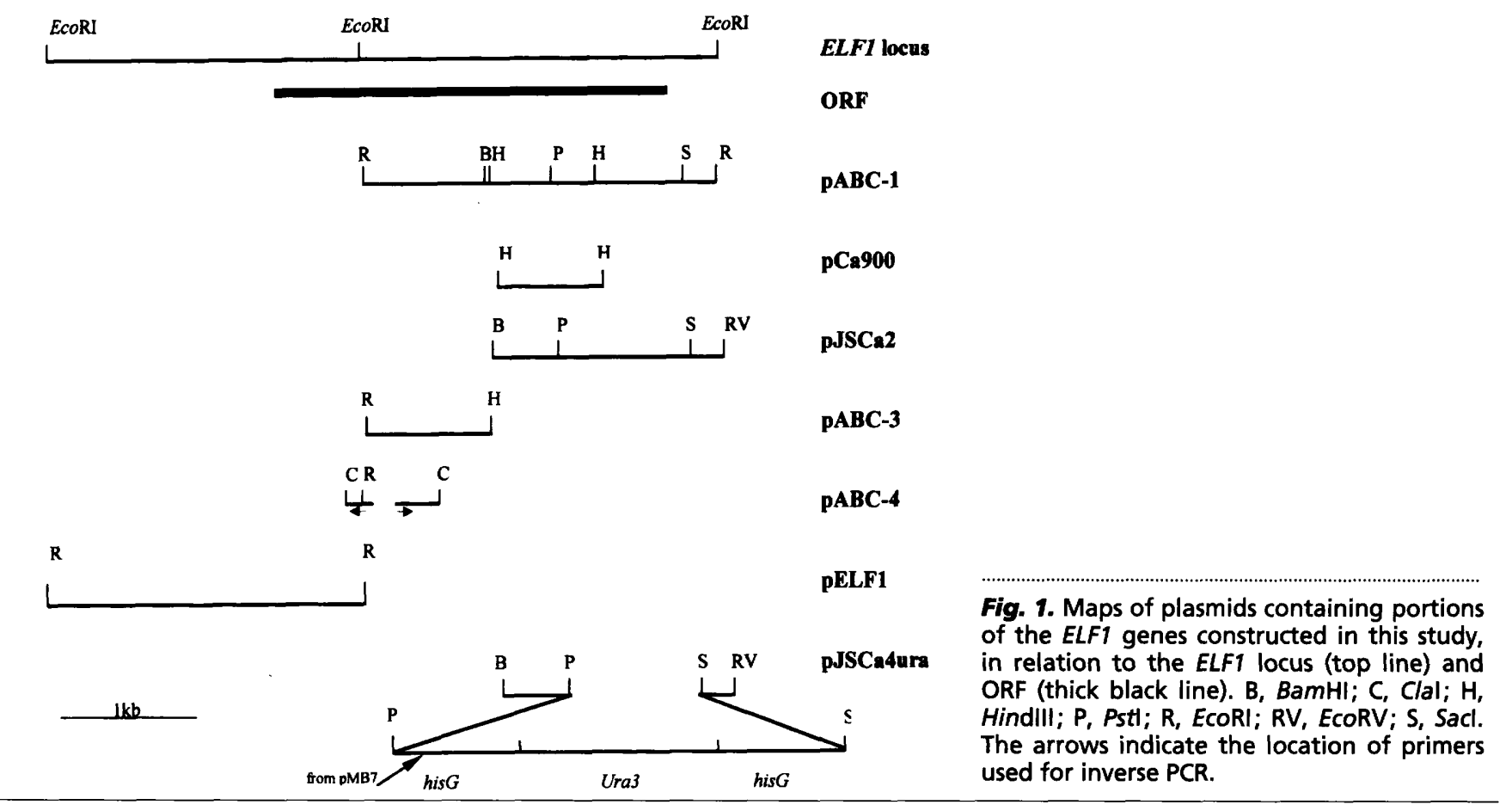

Southern analysis. DNA was digested to completion, electrophoresed on $1 \%$ agarose gels and transferred to a nylon membrane by capillary action using a 'dry' method. Gels were soaked in $0.5 \mathrm{M} \mathrm{NaOH}, 1.5 \mathrm{M} \mathrm{NaCl}(2 \times 15 \mathrm{~min})$, then in $1 \mathrm{M}$ ammonium acetate $/ 0.02 \mathrm{M} \mathrm{NaOH}(2 \times 30 \mathrm{~min})$ and the DNA transferred to preincubated nylon membranes (GeneScreen Plus; Dupont, or Nytran; Schleicher and Schuell) without a buffer chamber for $1 \mathrm{~h}$. DNA was fixed onto the membranes using UV or by baking at $80^{\circ} \mathrm{C}$. Prehybridization was performed at $65^{\circ} \mathrm{C}$ for at least $5 \mathrm{~min}$ in $7 \%$ SDS, $0.5 \mathrm{M}$ sodium phosphate, $\mathrm{pH} 7 \cdot 2,1 \mathrm{mM}$ EDTA (Monod et al., 1994). DNA probes were labelled with $\alpha^{-32} \mathrm{P}$ using Ready-to-Go DNA Labelling Beads (-dCTP) (Pharmacia) or Prime-It RmT Random Primer Labelling kit (Stratagene). Membranes were hybridized in the same buffer for $16-24 \mathrm{~h}$ at $65^{\circ} \mathrm{C}$. Blots were washed twice for $15 \mathrm{~min}$ in $0.1 \times \mathrm{SSC}, 1 \% \mathrm{SDS}$ at $65^{\circ} \mathrm{C}$.

Plasmid construction. The plasmids constructed for this study are shown in Fig. 1. Plasmid pABC-1 was constructed by ligating the $3.2 \mathrm{~kb}$ EcoRI fragment isolated from the $\lambda \mathrm{gt} 11$ library into pBluescript SK + (pSK + ; Stratagene). pCa900 consists of an internal HindIII fragment from pABC-1, which hybridized with $\lambda \mathrm{E} 41$, ligated into $\mathrm{pSK}+$. For sequencing purposes, two subclones of pABC-1 were constructed. pABC1 was digested with EcoRI and BamHI and the $3^{\prime} 2 \cdot 2 \mathrm{~kb}$ fragment was ligated into $\mathrm{pSK}+$ to give $\mathrm{pABC}-2$. The plasmid pABC- 3 was constructed by ligating the $5^{\prime} 1.1 \mathrm{~kb}$ EcoRIHindIII fragment from pABC- 1 into $\mathrm{pSK}+$. The $3^{\prime}$ end of the insert of $\mathrm{pABC}-3$ overlaps with the $5^{\prime}$ end of the insert of pABC-2.

To obtain sequence upstream of ELF1, inverse PCR was performed (Silver, 1992). SC5314 genomic DNA (20 $\mu \mathrm{g}$ ) was digested with ClaI at a final concentration of $50 \mu \mathrm{g} \mathrm{DNA} \mathrm{ml}^{-1}$ and 0.2 units ClaI ml ${ }^{-1}$; circularization of the genomic ClaI fragments was performed at $10 \mu \mathrm{g} \mathrm{DNA} \mathrm{ml}^{-1}$ with 400 units of T4 DNA ligase (New England Biolabs). Between $0 \cdot 1$ and $0.5 \mu \mathrm{g}$ of ligated DNA was PCR amplified with $1 \mu \mathrm{M}$ primer and Taq DNA polymerase according to the manufacturer's instructions (Life Technologies). Abc4b, the upstream primer was located
$119 \mathrm{bp}$ upstream of the EcoRI site. The downstream primer Abc3 was located $312 \mathrm{bp}$ downstream of the EcoRI site. Locations of primers are shown in Fig. 1 and Table 2. The expected 800 bp product was subcloned by blunt ligation into pNoTA/T7 using a PCR cloning kit (5 prime $\rightarrow 3$ prime) resulting in plasmid pABC-4. pELF1 in pSK + phagemid was excised from a tertiary positive plaque from the Lambda Zap II SC5314 library probed with pABC-4.

To obtain disrupted strains, a transforming plasmid was constructed. Plasmid pMB7 (Fonzi \& Irwin, 1993) was kindly donated by William Fonzi (Georgetown University). pSK + was digested with SacI, blunt-ended with T4 DNA polymerase and religated to give $\mathrm{pSK}+$ deleted of the SacI restriction site $(\mathrm{pSK}+\Delta \mathrm{SacI}) \cdot \mathrm{pABC}-1$ was cut with $B a m \mathrm{HI}$ and EcoRV and ligated into $B a m \mathrm{HI} / E c o \mathrm{RV}$-digested $\mathrm{pSK}+\Delta S a c \mathrm{I}$ to give plasmid $\mathrm{pJSCa}$. The internal $1.2 \mathrm{~kb}$ PstI-SacI fragment of pJSCa2 was removed and replaced with the hisG(I-SceI)URA3-hisG(I-SceI) insert from pMB7 to give pJSCa4ura.

DNA Sequencing. Double-stranded and single-stranded DNA was sequenced by the dideoxy chain termination method (Sanger et al., 1977) using the Sequenase version $2.0 \mathrm{kit}$ (Amersham) and $\left[{ }^{35} \mathrm{~S}\right] \mathrm{dATP} \alpha \mathrm{S}, 1 \mu \mathrm{g}$ single-stranded M13 or 3-5 $\mu$ g denatured plasmid and M13 commercial sequencing primers or synthetic oligonucleotide primers. For initial comparison with databases, $\mathrm{pCa} 900$ was sequenced with T3 and T7 primers. pABC-2 was cut with BamHI and EcoRI and ligated into M13mp18 and M13mp19 (Life Technologies) to sequence both strands. The Cyclone I Biosystem (IBI) was used to produce sequentially overlapping clones. M13 clones were sequenced with M13 forward and reverse commercial primers. pABC-3 was sequenced using the T3 and T7 primers. Additional sequence was obtained with the synthetic oligonucleotide, $\mathrm{Abc} 3$ (see above). pABC-4 was sequenced with T7 and with the commercial M13-40 primer included in the Sequenase kit. pELF1 was sequenced with the T3 and T7 primers, to identify overlapping sequence with pABC-4. The rest of the ORF was sequenced with the specific internal primers (Life Technologies) ElfR1, ElfR2, ElfR3, ElfR4 and 
Table 2. Primer sequences used in this study

\begin{tabular}{|lcl|}
\hline $\begin{array}{l}\text { Primer } \\
\text { name }\end{array}$ & Position & \multicolumn{1}{c|}{ Sequence $\left(\mathbf{5}^{\prime} \mathbf{3}^{\prime}\right.$ ) } \\
\hline Elf121 & $-228--208$ & CGGTTATCGGGAAACGTTGTC \\
Elf318 & $-22-+9$ & CACACACACTCGACTATTGACAATGTCCAAG \\
ElfR4 & $301-272$ & GTGGAACTTTGGTTAGTGTTATTATTATAG \\
ElfR1 & $559-538$ & ATTTACTTCAATTTCCATTCAT \\
ElfR2 & $595-575$ & CTAAGTCAGGACTTTTAGGTTTC \\
ElfR3 & $625-602$ & TGAATGATTAATAAAGCTCCTTCT \\
ElfF1 & $602-625$ & AGAAGGAGCTTTATTAATCATTCA \\
Abc4b & $951-935$ & ATAAATCAGTCAATACC \\
Abc3 & $1154-1173$ & ATTAGTCCCCATTTTAGATA \\
495R & $1173-1154$ & TATCTAAAATGGGGACTAAT \\
ElfDR2 & $3006-2988$ & TCACTGATGGAGTTAATTC \\
ElFDR1 & $3598-3579$ & TCATACGCGTCTATATAACTCGATCCTCATC \\
3929R & $3928-3909$ & ATGAGATATTGTCGTTGTTG \\
Oligo(dT) & - & GACAACTAGTCTCGA $(\text { T })_{17}$ \\
\hline
\end{tabular}

1 MSKSFDDFIK QQKQQQSKPK GFGYRNNNQG GYNYNQAYGN VPTFQPGNQQ FQYQGGYNQG 60

61 FNQQQYQYOG QGYNNQGYNS NNRYNNSNNY NYNNNTNQSS TISTPVDSLP TSGRSTPNPN

121 ASTTSLTSLN TALAKLNVSN IPFEENLSNI EKAGKIAEIR PEVETIVKII DEQEDLCIIN

181 EWKLNEILKS LLKPKSPALV KEGALLIIQQ LATKFGGQTP KEAYLLQFLS TAYDMFTDKD

241 KNVVKAAKSA TDALFGIYPV EALGSIVLDE YLTIFKSGAK WNSKVAALVN FDKLIDDVPA

301 DILEMKEIDV VPVLTDLSTD FKPELAKAGL STLKKFVKVL DNLDLQNKYD LIVDTLADPK KVTDCIKNLS SVTFVAEVTE PALSLLVPIL DKSLKMSSSS NDELRQTVMV TKNLTRLVNN KREIEQFIPI LLPGVEKVVN NASLPEVREL AGKALKVĹKD AENEQTDGKF HGRITLEQAE KFYTEDIPDE QHQQPVOLLK DDILKKYLAT VLQSMLMSML GTLQEYLMMA TNNNETSSQL VVTHVKNLFN PESAADNEND DGAVVIVDAD FSLAYGTRML LNKTKLRLLK GLRGLCGRN GAGKSTLMRA ISKGQLEGFP TADELKTCFV EHKLQGSEAD MDLVSFIGSD PELANVGREE IEQALKDVGF PDERLQQQVG SLSGGWOOK RLARAMAMKA EVLLLDEPTN HLDVANVKWL QDYLVENTES LICSHDSGEL DAVCTDIIHY ENKKLAYYKG NLSEFVKIKP EGKSYYTLTD SNVKMAFPPP GILTGVKSNT RAVARMSNVT FAYPGADKPS LKNVSCSLSL SSRVAILGPN GAGKSTLIKL LTAELVPQEG KVEKHPNLRI GYIAQHALQH VEQHKEKTCQ SIFTWRYREG DDREVLLKES RKVSDEEQEM MKKEIDIGDG RGKRAIEALV GRQKLKKSFQ YEVKWKYWLP KYNSWVPKEV LLEHGFDKLI QKFDDHEASR EGLGYRELTP SVIRKHFEDV GLDGDIADHT PHLLVLDE PTNYLDRDSL GGLAMA RREW NGGVUMISHN
Fig. 2. Deduced amino acid sequence of ELF1. The nucleotide-binding domains $A$ and $B$ are boxed. The ATP transporter consensus sequence is in bold. The region deleted from the CAJS5 mutant is italicized (amino acids 851-1192).
ElfF1(Table 2) using $\left[{ }^{35} \mathrm{~S}\right] \mathrm{dATP} \alpha \mathrm{S}$ and the Sequenase 2.0 or ThermoSequenase cycle sequencing kit (Amersham). Analysis of sequence data was performed using the University of Wisconsin GCG sequence analysis software programs (Devereux et al., 1984). Nucleotide database searches were performed using BLAST (Altschul et al., 1990).

PCR Analysis. To confirm the ELF1 deletion in the genome, $0 \cdot 1 \mu \mathrm{g}$ genomic DNA was PCR amplified with reverse primers located in the deleted region (ElfDR1), $5^{\prime}$ of the deletion (495R) or $3^{\prime}$ of the deletion (3929R). In all three amplifications the forward primer was Elf318.
RT-PCR. One microgram of RNA isolated from SC5314, CAJS2 or CAJS5 was treated with DNaseI (amplification grade; Life Technologies) according to the manufacturer's instructions, in a volume of $10 \mu \mathrm{l}$. The reaction was stopped and $1 \mu \mathrm{l}$ saved to check for contamination with DNA. The remainder was annealed to $495 \mathrm{R}$ or an oligo(dT) primer and reverse transcribed in a final volume of $20 \mu \mathrm{l}$ with Superscript II RNase H-Reverse Transcriptase (Life Technologies) according to the manufacturer's instructions. Two microlitres of this reaction was directly amplified with $495 \mathrm{R}$ and ElfF1, or with a reverse primer located in the deleted region ElfDR 2 and the 
forward primer Abc3. PCR was perfomed with the upstream forward primer Elf121 to verify the absence of DNA. PCR amplifications were performed with $T a q$ DNA polymerase (Life Technologies); annealing was at $52^{\circ} \mathrm{C}$.

PFGE and I-Scel digestion. PFGE was performed with the CHEF-DRII pulsed-field electrophoresis system and Pulsewave 760 Switcher (Bio-Rad). Agarose plugs of chromosomal DNA from desired strains were prepared as described by Wickes et al. (1991a). Plugs were pre-equilibrated in 0.5 $\times$ TBE prior to loading in a $0.75 \%$ agarose gel. Gels were run at $75 \mathrm{~V}$ with a linear ramping of the switching interval from $300 \mathrm{~s}$ to $1400 \mathrm{~s}$ for $144 \mathrm{~h}$ at $13^{\circ} \mathrm{C}$. Fresh running buffer was added after $72 \mathrm{~h}$. Southern transfer of pulsed field gels was performed as suggested by the manufacturer (Bio-Rad). To determine the site of integration of transforming DNA, chromosome plugs were digested with the meganuclease I-SceI (Boehringer Mannheim Biochemicals) as described by Fonzi \& Irwin (1993).

\section{RESULTS}

\section{Isolation of ELF1}

A protein which binds the human complement breakdown product $\mathrm{C} 3 \mathrm{~d}$, and therefore has binding functions similar to the mammalian complement receptor 2 (CR2), has been described (Saxena \& Calderone, 1990). To isolate the corresponding gene from C. albicans, genomic DNA from strain 4918 was digested with EcoRI and HindIII and probed with a $1.8 \mathrm{~kb}$ internal EcoRI fragment of $\lambda E 41$, which is a cDNA clone of the human CR2 gene (Moore et al., 1987). The $1.8 \mathrm{~kb}$ probe hybridized with EcoRI fragments of $11,8,3.2$ and $1.3 \mathrm{~kb}$ and HindIII fragments of 9.5 and $0.7 \mathrm{~kb}$ (data not shown). The $3.2 \mathrm{~kb}$ EcoRI fragment was isolated by plaque hybridization from an EcoRI genomic library constructed in $\lambda \mathrm{gt} 11$. Further analysis showed that $\lambda \mathrm{E} 41$ hybridized with a HindIII fragment of approximately $900 \mathrm{bp}$, contained within the EcoRI fragment (Calderone et al., 1992). This HindIII fragment was subcloned and partially sequenced. At the nucleotide level, overall homology between the human CR2 gene and ELF1 was not significant. However, a 36 bp stretch demonstrated a $76 \%$ identity, which may be the region that was recognized in Southern and library screens. No homology with the human CR2 gene was identified in a BLAST search (Altschul et al., 1990). On the other hand, significant homology existed along the entire sequence at both the nucleotide and amino acid levels with the $\mathrm{ABC}$ genes. Consequently, it was of interest to continue

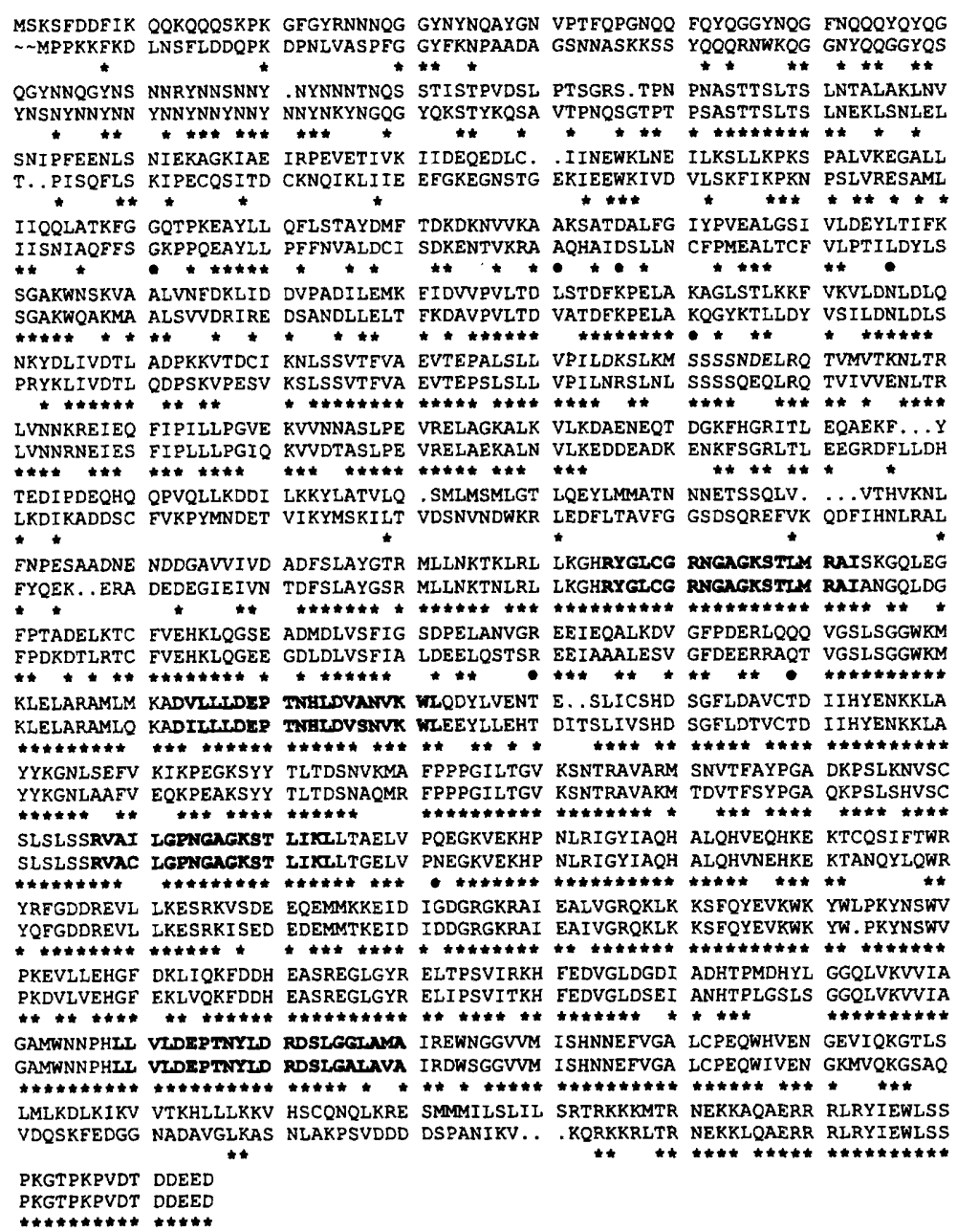

Fig. 3. Comparison of ELF1 (Elf) with the S. cerevisiae ORF, SCYPL226W (SC; Genbank accession no. Z73582) using the GCG PILEUP program. Amino acid residues which are identical between ELF1 and SCYPL226W are denoted by asterisks. Walker $A$ and $B$ regions are in bold. 
(a)
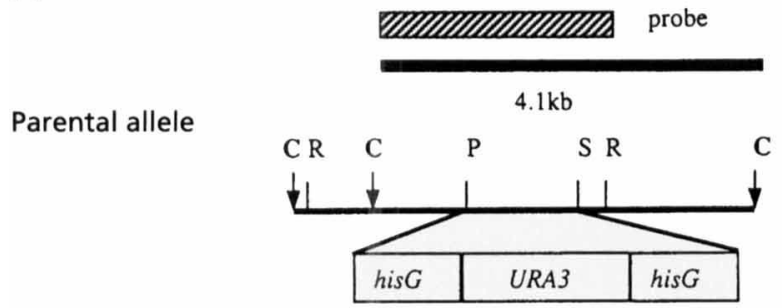

Disrupted allele

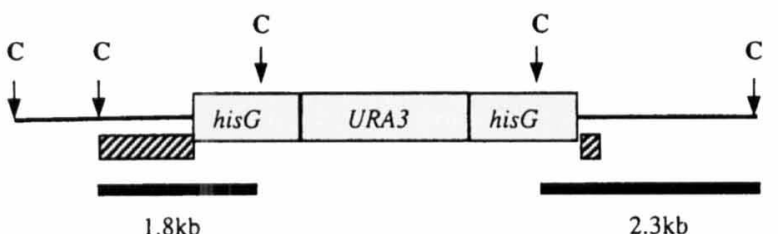

$1.8 \mathrm{~kb}$

FOA segregant

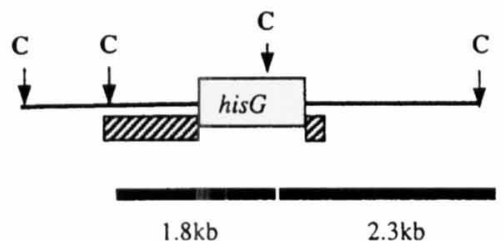

(b)

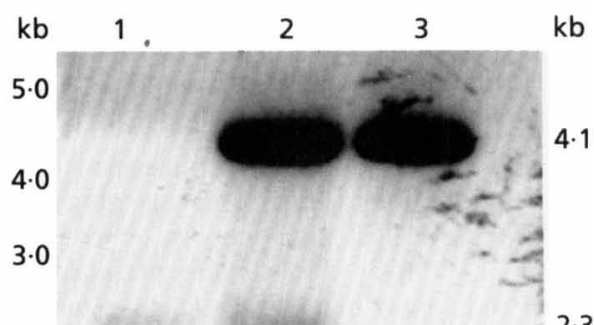

$2 \cdot 0$

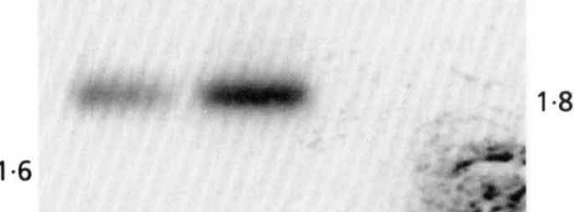

Fig. 4. Disruption of the ELF1 gene. (a) Restriction map of the ELF1 locus and the hisG-URA3-hisG insertion positions. Position of Clal (C) sites are shown in parental allele, disrupted allele and FOA segregant. An internal $2.5 \mathrm{~kb} C l a l-E c o R I$ fragment was used as a hybridization probe (indicated by hatched rectangle). Genomic DNA expected to hybridize to the probe is shown as a hatched rectangle. Thick black lines indicate the Clal fragments recognized by the probe on a Southern blot. $C=C l a l$ sites, $R=E c o R I$ sites, $S=S a c l$ sites. (b) Southern blot analysis of Clal-digested genomic DNA. DNA was isolated from CAJS5 (lane 1), CAJS2 (lane 2) and CAI4 (lane 3). The size of the fragments in kilobases is indicated on the right and migration of standards are noted on the left. Since there is a Clal site in the hisG gene, digestion of disrupted alleles results in two fragments of $1.8 \mathrm{~kb}$ and $2.3 \mathrm{~kb}$ that hybridize with the elf probe, instead of $4.1 \mathrm{~kb}$ as seen in the non-disrupted allele; see (a).

characterizing this gene. The strategy for the complete sequence analysis of the $3.2 \mathrm{~kb}$ EcoRI fragment and the upstream sequence is described in Methods. To obtain the full gene, a section between EcoRI sites was obtained by inverse PCR (pABC-4). Southern analysis of EcoRIdigested genomic DNA with ${ }^{32}$ P-labelled pABC-4 showed two bands, one at $3.2 \mathrm{~kb}$ as expected and a second at $2.8 \mathrm{~kb}$ (data not shown). pABC-4 was used to screen an EcoRI-digested SC5314 genomic DNA library constructed in Lambda Zap II. Positive plaques were excised, plasmids isolated and digested with EcoRI. The insert of one clone, pELF-1, migrated at $2 \cdot 8 \mathrm{~kb}$, as predicted. The remainder of pELF-1 $(1 \cdot 2 \mathrm{~kb})$ was sequenced with the T3 and T7 primers. The T7 sequence matched $\mathrm{pABC}-4.1 \cdot 2 \mathrm{~kb}$ of pELF-1 was then sequenced with specific internal primers to obtain the full ORF (see Methods).

ELF1 encodes a putative protein of 1192 amino acids. GCG analysis of the deduced amino acid sequence (Fig. 2) demonstrated the presence of two ATP/GTP-binding site motifs and an $\mathrm{ABC}$ transporter consensus sequence located between the Walker A and B regions of the first ATP-binding site. BLAST analysis (Altschul et al., 1990) indicates that ELF1 shows significant homology to the $\mathrm{ABC}$ gene family, and in particular, the S. cerevisiae ORF, SCYPL $226 \mathrm{~W}$ (63\% identity, $70 \%$ similarity), the EF-3 genes ( $36 \%$ identity, $46 \%$ similarity) and GCN 20 . The homology between ELF1, SCYPL226W and the EF3 genes is more extensive than with the MDR-like genes. Comparison of the deduced protein sequences of ELF1 and SCYPL226W is shown in Fig. 3. In addition to the length of the gene and spacing between Walker A and B regions, the majority of the identity is seen in the ATPbinding domains. The $5^{\prime}$ ends of the genes are the least similar. However, the final 30 amino acids at the $3^{\prime}$ ends are identical in ELF1 and SCYP1226W but not in C. albicans EF-3 (not shown). This region in EF-3 is proposed to be responsible for ribosomal interaction (Chakraburtty et al., 1995). Northern analysis confirmed that a $3.6 \mathrm{~kb}$ RNA was produced in yeast, pseudohyphal and hyphal forms. The level of expression did not vary 
significantly during serum-induced morphogenesis (data not shown).

\section{Construction of disrupted strains}

The function of the S. cerevisiae ORF, SCYPL226W, has not yet been determined. To study the function of the gene product of ELF1, a disrupted mutant was constructed using the methodology described by Fonzi \& Irwin (1993). pABC2, which contains $70 \%$ of the open reading frame of ELF1 and the $3^{\prime}$ downstream sequence, was cloned into pSK + (see Fig. 1). pJSCa4ura was digested with NotI and XhoI (located in the polylinker), to release the ELF1 disruption cassette, and $15 \mu \mathrm{g}$ was used to transform CAI4. Ura ${ }^{+}$transformants $(12$ out of 80) were analysed for integration by Southern hybridization (Fig. $4 b$, lane 2). Three transformants underwent the desired recombination event. Spontaneous Ura ${ }^{-}$derivatives of two of the resulting heterozygotes, CAJS1 and CAJS2, were selected on YNB containing $1 \mathrm{mg} \mathrm{FOA} \mathrm{ml}^{-1}$ (Fonzi \& Irwin, 1993). FOA is toxic for strains containing URA3 genes. Therefore, only those colonies which have lost the URA3 gene by intrachromosomal recombination will grow on YNB + FOA. Segregants were analysed by Southern hybridization. Of 15 FOA segregants analysed, four lost the URA3 gene and one copy of the hisG gene (see Fig. 4a). Two segregants, CAJS1E and CAJS2D, were transformed with pJSCa4ura in five separate experiments. Out of a total of $36 \mathrm{Ura}^{+}$transformants, one had lost the second wild-type allele and was designated CAJS5 (Fig. 4b, lane 1).

PCR analysis of genomic DNA confirmed the presence of a disrupted allele in CAJS5. Genomic DNA isolated from strains SC5314, CAJS2 and CAJS5 was PCR amplified with a forward primer, ElfF1, and a primer located in the deleted region, ElfDR1. No product was seen in CAJS5. However, PCR with reverse primers $5^{\prime}$ (495R) or $3^{\prime}(3929 R)$ of the deletion did result in the expected products (data not shown). Since only the 3' end of the gene was deleted, RT-PCR was performed to determine whether a truncated form of the gene was expressed (Fig. 5). RNA isolated from SC5314, CAJS2 and CAJS5 was reverse transcribed with an oligo(dT) primer. This product was then PCR amplified with a forward primer, ElfF1, and the reverse primer 495R. A $0.5 \mathrm{~kb}$ product was observed in both the parent and disrupted strains (Fig. 5). To confirm that this product did not result from genomic DNA, PCR amplification with a primer located in the promoter region (Elf121) and at $1173 \mathrm{bp}(495 \mathrm{R})$ resulted in no product in CAJS5 (lane 7) or the other strains (not shown), confirming the absence of contaminating genomic DNA. PCR of genomic DNA with the same primers acted as a control. To confirm that a full-length transcript was not present in CAJS5, PCR of the cDNA from the three strains was also performed with a reverse primer located in the deleted region, ElfDR2, and Abc3 (Fig. 5). The expected $2 \cdot 2 \mathrm{~kb}$ product was seen in the parental and single disruptant, but not the double disruptant (lane 6).
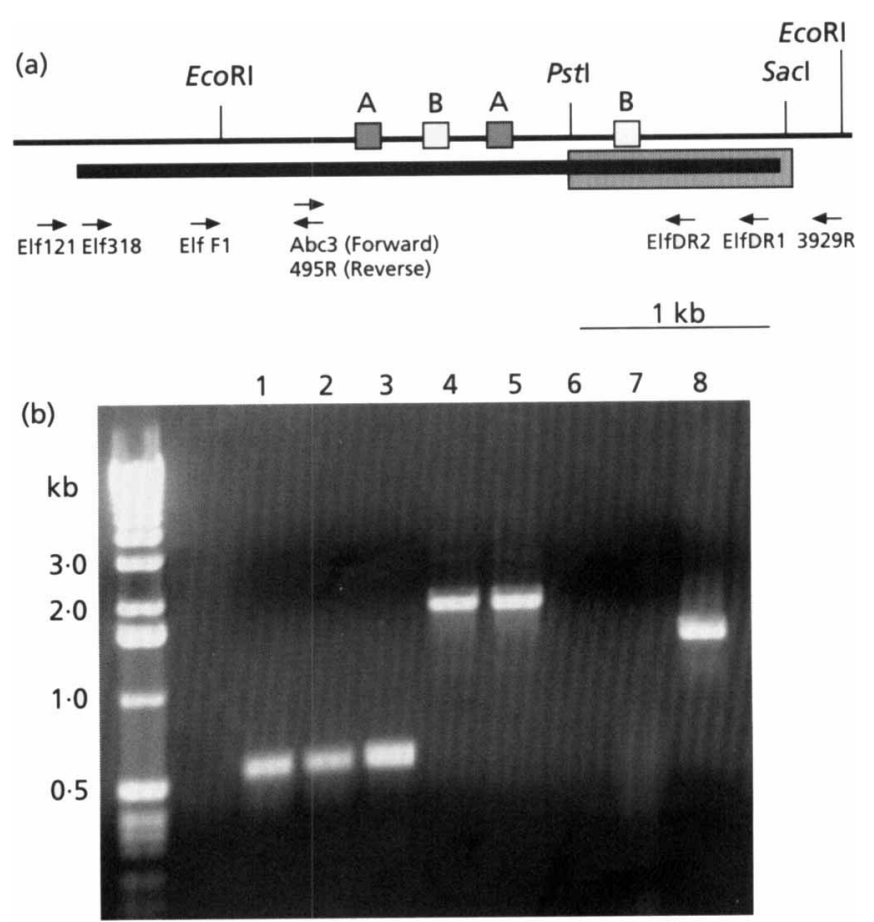

Fig. 5. PCR analysis of the ELF1 gene. (a) Line diagram showing the $4.4 \mathrm{~kb}$ of sequenced genomic DNA at the ELF1 locus. The location of the ORF (1-3573 bp) (heavy line) and deleted region (2559-3763 bp) (grey rectangular box) and Walker A (grey square boxes) and $B$ (white square boxes) regions are shown. PCR amplification of genomic DNA to confirm the deletion was done with Elf318 and a primer in the deleted region, EIfDR1, 5' of the deleted region, $A b C 3$, or $3^{\prime}$ of the deleted region, 3929R. To determine whether a truncated form of the ELF1 gene was expressed, RT-PCR was performed with the oligo(dT) primer and DNase-treated RNA isolated from SC5314 (lanes 1 and 4), CAJS2 (lanes 2 and 5) and CAJS5 (lanes 3,6 and 7). The CDNA was PCR amplified with a forward primer, ElfF1, and a reverse primer, 495R, (lanes 1-3), or a forward primer, $A b c 3$, and a reverse primer in the deleted region, ElfDR2 (lanes 4-6). To confirm that genomic DNA was not amplified, CDNA was PCR amplified with a forward (Elf121) and reverse (495R) primer. No product was seen in CAJS5 (lane 7) but the expected $1.3 \mathrm{~kb}$ product was seen when genomic DNA was used as the template (lane 8).

RT-PCR was also performed with specific elf primers. The same results were obtained: a truncated product was observed with RNA isolated from CAJS5 when RTPCR was performed with the reverse primer at $1154 \mathrm{bp}$ but no product with the reverse primer at $3006 \mathrm{bp}$.

PFGE confirmed that disruption of the gene was not a result of gross chromosome rearrangements (Fig. 6a). Southern analysis of the pulsed-field gel localized ELF1 to chromosome R (Fig. 6b). Since I-SceI is present in the bis $G$ gene of the disruption cassette but not elsewhere in the Candida genome, digestion with I-SceI results in cleavage at the site of the disrupted gene. Therefore, if the gene is correctly disrupted, the chromosome will be restricted with I-Sce-I. Chromosome plugs of CAJS2 and CAJS5 were digested with I-SceI, subjected to PFGE, Southern blotted and probed with the EcoRI insert of 

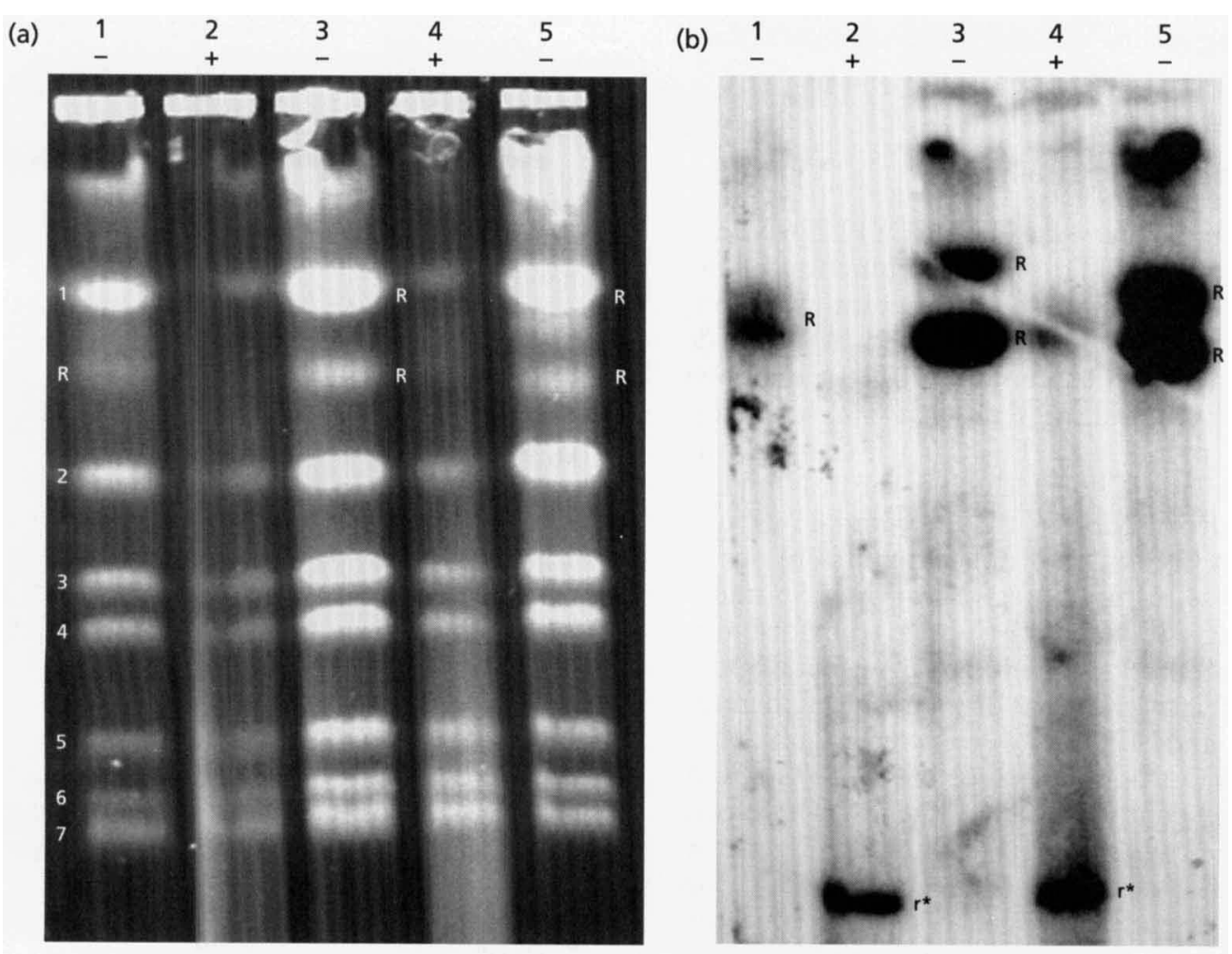

Fig. 6. PFGE of transformed and I-Scel-digested strains. Chromosomal DNA was prepared from the following strains: CAI4 (lane 1), CAJS5 (lanes 2 and 3) and CAJS2 (lanes 4 and 5). DNA was incubated with (+) or without (-) I-Scel. (a) The chromosome bands were visualized with ethidium bromide. Chromosomes are numbered on the left. The position of the $R$ chromosome $(R)$ or digested $R$ chromosome $\left(r^{*}\right)$ is indicated. (b) Southern blot of the gel in (a) hybridized with the $3.2 \mathrm{~kb}$ EcoRI fragment from $\mathrm{PABC}-1$.

pABC-1. Fig. 6(b) shows that integration corresponds with localization of the ELF1 gene on chromosome R. Fig. 6 shows that chromosome R migrates differently in the three strains, and in CAJS5, appears to comigrate with chromosome 1 . It has been reported that chromosome $\mathrm{R}$ and chromosome 1 comigrate in some strains (Wickes et al., 1991b). However, digestion with I-Scel and hybridization with ELF1 clearly shows the faster migration of one digested chromosome in CAJS2 and both chromosomes in CAJS5.

\section{Phenotypical characterization of CAJS5}

CAJS5 was grown in YPD and YNB media supplemented with uridine. Growth was slower compared to CAF2-1 (the URA3 heterozygote), and CAJS2 (ELF1::elf1 URA3:ura3), in both liquid (Fig. 7) and solid media (data not shown) but was comparable to the $\mathrm{Ura}^{-}$strain, CAI4. The intermediate growth rate of CAJS2 (URA3/ura3) appears to be due to a dosage effect of the ELF1 gene and not the URA3 gene, since in a similar experiment, the growth rate of CAF2-1 (URA3 heterozygote) was the same as SC5314 (data not shown). Cell growth based on $\mathrm{OD}_{550}$ resulted in the same differences between growth curves (data not shown).
There is a significant difference in colony growth between CAJS5 and CAF2-1; CAJS5 colonies are smaller and more heterogeneous in size. Microscopic examination of both small and normal-sized colonies revealed that yeast forms of CAJS5 are variable in shape: while normal budding cells were observed, many cells were large and misshapen, and multiple buds were common (Fig. 8). There was no obvious difference in the proportion of cell types in small and normal-sized colonies. However, the small colonies normally contained $80 \%$ fewer cells. Aggregated forms were also observed which could contribute to the slower growth rates of CAJS5 (see Fig. 7). Aberrant yeast forms made up between $50-60 \%$ of the population in CAJS5, compared to $20-30 \%$ in CAJS2 and less than $10 \%$ in SC5314, during the first $6 \mathrm{~h}$ growth in YPD. During the next $3 \mathrm{~h}$, aberrant forms in CAJS5 and CAJS2 decreased to $15 \%$ and $8 \%$, respectively. Aberrant yeast forms were viable as determined by staining with methylene blue. An equivalent number of cells from 2 and $6 \mathrm{~h}$ cultures of CAJS5 and CAF2-1 were plated on YPD. Again, the viability of the cultures was equivalent but the CAJS5 colonies were significantly smaller. Aberrant cells were no more sensitive than normal cells to $1 \%$ SDS or high salt (data not shown). 


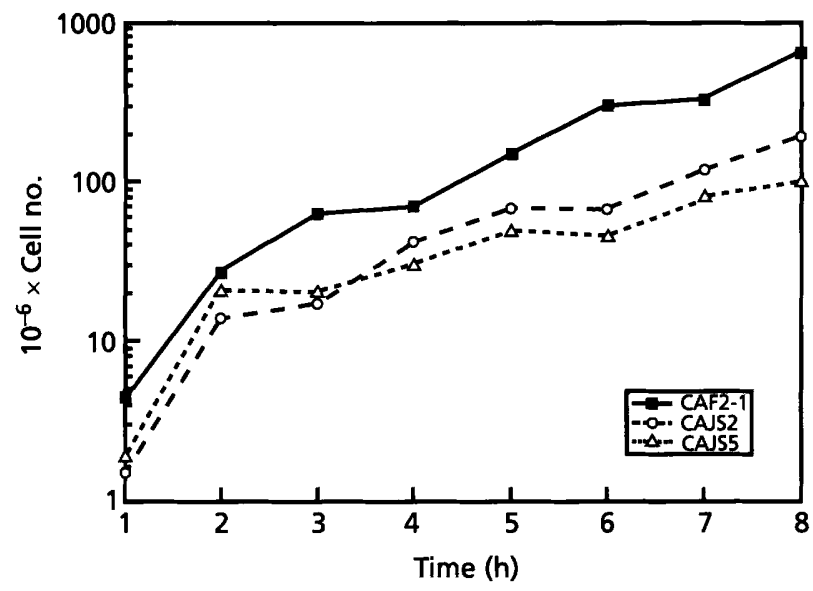

Fig. 7. Growth of $C$. albicans strains in YPD. Cultures $(4 \mathrm{ml})$ were inoculated with $1 \times 10^{6}$ cells from overnight cultures. Samples were taken and cells counted with a haemocytometer at the times indicated. These data are representative of three separate experiments. Similar results were obtained when cells were grown in YNB, or in the presence of uridine, or when cell concentration was determined by $\mathrm{OD}_{550}$ measurement. The growth curve of SC5314 was identical to that of CAF2-1.

\section{DISCUSSION}

$\mathrm{ABC}$ membrane pump proteins are found in a variety of micro-organisms including C. albicans, as well as in mammalian cells. Structurally, these proteins are composed of two repeated halves, each of which includes a hydrophilic, cytoplasmic domain and a hydrophobic domain containing six transmembrane regions. Each half consists of one Walker A (P-loop), one Walker B and an ATP-binding domain, typical of the ATP-binding cassette transporters (Higgins, 1992). Sequence analysis of the ELF1 gene revealed a similar structural arrangement. Two ATP/GTP-binding site domains and an $\mathrm{ABC}$ transporter consensus sequence located between the Walker A and B domains in the first half were identified in ELF1. The homology of ELF1 described in this report was most extensive to SCYPL226W, an ORF of unknown function recently reported from $S$. cerevisiae; a lower level of homology was seen to EF-3. Homology with the MDR-like genes was low, but still significant.

To resolve questions about the function of ELF1, in the light of its homology with other genes, we constructed disrupted strains and examined the role of ELF1 in growth. Since the disruption is at the $3^{\prime}$ end of the gene and some $A B C$ transporters can function as half molecules, the double-disruptant may not be a true null. We found that disrupted strains grew less well than the wild-type, and heterozygotes demonstrated an intermediate growth rate. The growth impairment was observed on agar media as the presence of smaller-thannormal and pin-point-sized colonies. In liquid media, cells were pleiotropic in size and morphology. While some budding cells were normal in size, a significant number were larger and formed elongated buds. Some cells were swollen and elongated with a slight constriction in the middle, resembling a peanut shell, appearing as if they could not form a bud wall. The swollen size could result from a growth control defect or, alternatively, a deregulation of efflux/influx proper-
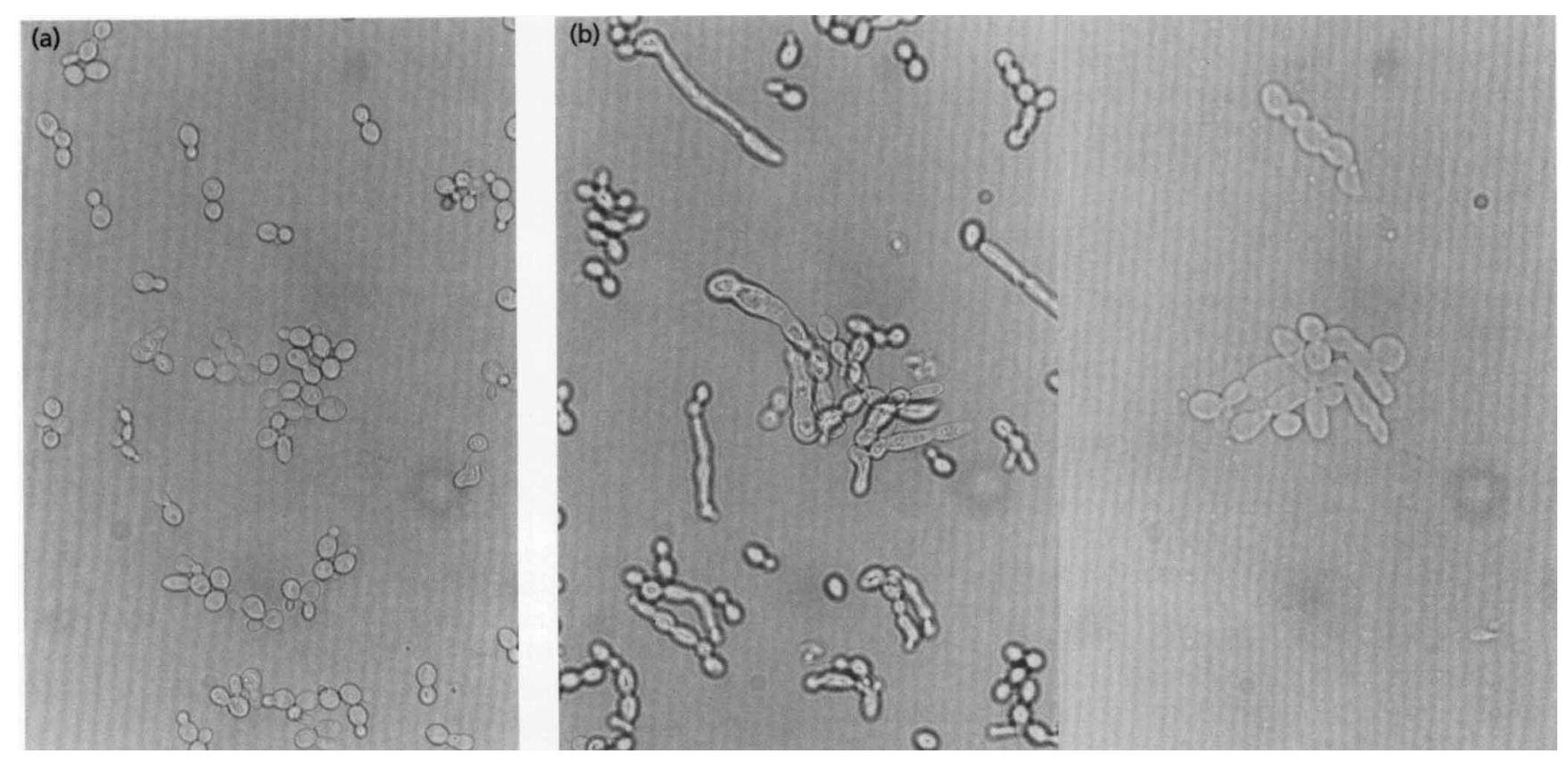

Fig. 8. Photomicrographs of CAJS5 and SC5314 ( $125 \times$ magnification). YPD + uridine was inoculated with an overnight culture of SC5314 (a) or CAJS5 (b) to a starting density of $10^{6}$ cells ml-1 and incubated at $30^{\circ} \mathrm{C}$ for $3 \mathrm{~h}$. The variability in the morphology of CAJS5 can be seen here. 
ties. The aberrant cells made up $50 \%$ of the population early in culture $(2-6 \mathrm{~h})$. The lower percentage of aberrant cells at $7-9 \mathrm{~h}$ is probably due to the division of 'normal' cells. The pleiotropy may be due to the absence of the ELF1 gene or alternatively, because only the 3 ' end of the gene is deleted in CAJS5. The normal cells seen in the population could be the result of the action of the truncated ELF1 gene. However, the truncated activity must be insufficient for the entire population. Cassettes which will disrupt the $5^{\prime}$ region of the gene are now being constructed. At this point, it is impossible to determine whether the abnormal growth in ELF1 mutants is due to an altered permeability in the cell, or whether the ELF gene product affects the expression of specific genes required for optimal growth. It is not yet known whether a single compound can restore a normal growth pattern to CAJS5, or whether the absence of this gene results in a general deficiency in the transport of required metabolites to the correct components of the cell or export of toxic compounds from the cell. A genedosage effect is apparent, in that strains heterozygous for ELF1 show an intermediate growth rate and percentage of abnormally shaped yeast cells. Consequently, this gene may be a potential antifungal target, since its reduced expression may affect viability in the host.

Drug resistance and sensitivity in yeast have been linked to altered permeability (Fling et al., 1991). We compared strains CAJS2 and CAJS5 to SC5314 for sensitivity to amphotericin B, and three azoles, ketoconazole, fluconazole and miconazole, by the broth microdilution method for drug susceptibility (data not shown) (National Committee for Clinical Laboratory Standards, 1995). No significant differences in susceptibilities were seen. However, when the small colonies of CAJS5 were compared with the normal-sized colonies, preliminary data indicated that small colonies have a 100 -fold or greater resistance to miconazole and amphotericin $\mathrm{B}$. The $\mathrm{MIC}_{50}$ of normal sized and small colonies for miconazole was $0.008 \mu \mathrm{g} \mathrm{m}^{-1}$ and $0.4 \mu \mathrm{g} \mathrm{ml} \mathrm{m}^{-1}$, respectively, and for amphotericin $\mathrm{B}, 0.06 \mu \mathrm{g} \mathrm{ml}^{-1}$ and $>1 \mu \mathrm{g} \mathrm{ml}^{-1}$, respectively. No difference was seen with fluconazole and only a slight difference with ketoconazole. Others have shown that resistance to one azole does not necessarily confer resistance to azoles in general (McCullough \& Hume, 1995). The increased resistance in the small colonies to miconazole and amphotericin B, but not the other azoles could be due to their slower growth rate, associated with changes in transport (influx or efflux). In this case, ELF1 would have an effect opposite that of the Candida ABC genes, $C D R 1$ and $C D R 2$, in that increased expression of CDR1 and CDR2 is seen in fluconazole-resistant clinical isolates (Sanglard et al., 1995, 1997; White, 1997). $C D R 1$ but not CDR2 knockout mutants in C. albicans demonstrate hypersensitivity to a variety of antifungal agents, including azoles; strains deleted in both $C D R$ genes show increased sensitivity over $c d r 1$ null mutants (Sanglard et al., 1996, 1997). It is interesting to note that both ELF1 and CDR1 lack an $A B C$ signature sequence between the second set of Walker domains.
Although most of the $\mathrm{ABC}$ superfamily are transport proteins, a few are involved in UV repair and protein translation (Higgins, 1992). BLAST analysis identified significant homology between ELF1 and the fungal EF-3 genes. EF-3 is involved in the ATP-dependent interaction between aminoacylated tRNA and the ribosome A-site (Chakraburtty et al., 1995). After SCYPL226W and the EF-3 genes, GCN20 was the most homologous to ELF1, particularly at the ATP-binding sites. GCN20 is a positive regulator of the transcriptional activator protein GCN4, which is involved in general amino acid control. One function proposed for GCN20, like that for EF-3, is to facilitate the release of uncharged tRNA from the ribosome E site (Vasquez de Aldana et al., 1995). Therefore, ELF1 may play a role in polypeptide elongation. The abnormal morphology and increased resistance to some drugs may indicate an altered permeability of the cell. On the other hand, if the translation mechanism is altered, there may be a subsequent effect on the expression of genes for optimal growth. In either scenario, drug transport or translational control, the importance of ELF1 is apparent.

\section{ACKNOWLEDGEMENTS}

We would like to thank Gail McElhaney Feser for performing the drug susceptibility tests. This research was supported by a Public Health Grant to R.C. (NIH-NIAID-P01 AI37751) and by a Georgetown Research Starter Grant to J.S.

\section{REFERENCES}

Altschul, S. F., Gish, W., Miller, W., Myers, E. W. \& Lipman, D. J. (1990). Basic local alignment search tool. J Mol Biol 215, 403-410.

Balzi, E. \& Goffeau, A. (1994). Genetics and biochemistry of yeast multidrug resistance. Biochim Biophys Acta 1187, 152-162.

Boeke, J. D., LaCroute, F. \& Fink, G. R. (1984). A positive selection for mutants lacking orotidine- $5^{\prime}$-phosphate decarboxylase activity in yeast: 5 -fluoroorotic acid resistance. Mol Gen Genet 197, 345-346.

Calderone, R. A., Southard, S. \& Hale, C. (1992). The complement C3d-binding receptor (CR2) of Candida albicans: cloning and sequence analysis of a gene fragment homologous with a human CR2 cDNA clone. In Molecular Biology and its Application to Medical Mycology, pp. 23-30. Edited by B. Maresca, G. S. Kobayashi \& H. Yamaguchi. Taoromina, Italy: Springer (NATO ASI Series).

Chakraburtty, K., Ziehler, J., Sharma, N. \& Hopkins, A. S. (1995). Elongation factor 3: a new target for antifungal drugs. In Morphogenesis and Metabolism in Opportunistic Fungal Pathogens, pp. 324-331. Edited by J.-P. Latgé, R. Calderone, \& H. Yamaguchi.

Colthurst, D. R., Schauder, B. S., Hayes, M. V. \& Tuite, M. F. (1992). Elongation factor 3 (EF-3) from Candida albicans shows both structural and functional similarity to EF-3 from Saccharomyces cerevisiae. Mol Microbiol 6, 1025-1033.

Devereux, J., Haeberli, P. \& Smithies, O. (1984). A comprehensive set of sequence analysis programs for the VAX. Nucleic Acids Res 12, 387-395.

Fling, M. E., Kopf, J., Tamarkin, A., Gorman, J. A., Smith, H. A. \& Koltin, Y. (1991). Analysis of a Candida albicans gene that encodes a novel mechanism for resistance to benomyl and methotrexate. Mol Gen Genet 227, 318-329. 
Fonzi, W. A. \& Irwin, M. Y. (1993). Isogenic strain construction and gene mapping in Candida albicans. Genetics 134, 717-728.

Gietz, D., St. Jean, A., Woods, R. A. \& Schiestl, R. H. (1992). Improved method for high efficiency transformation of intact yeast cells. Nucleic Acids Res 20, 1425.

Gillum, A. M., Tsay, E. Y. H. \& Kirsch, D. R. (1984). Isolation of the Candida albicans gene for orotidine $-5^{\prime}$ phosphate decarboxylase by complementation of Saccharomyces cerevisiae ura3 and Escherichia coli pyrF mutations. Mol Gen Genet 198, 179-182.

Gottesman, M. M. \& Pastan, I. (1993). Biochemistry of multidrug resistance mediated by the multidrug transporter. Annu Rev Biochem 62, 385-427.

Hawser, S. P. \& Douglas, L. J. (1994). Biofilm formation by Candida species on the surface of catheter materials in vitro. Infect Immun 62, 915-921.

Higgins, C. F. (1992). ABC transporters: from microorganisms to man. Annu Rev Cell Biol 8, 67-113.

McCullogh, M. \& Hume, S. (1995). A longitudinal study of the change in resistance pattern and genetic relationship of oral Candida albicans from HIV-infected patients. J Med Vet Mycol 33, 33-37.

Manning, M. \& Mitchell, T. G. (1980). Strain variation and morphogenesis of yeast and mycelial-phase Candida albicans in low sulfate, synthetic medium. J Bacteriol 142, 717-719.

Matthews, R. C. (1994). Pathogenicity determinants of Candida albicans: potential targets for immunotherapy? Microbiology 140, 1505-1511.

Monod, M., Togni, G., Hube, B. \& Sanglard, D. (1994). Multiplicity of genes encoding secreted aspartic proteinases in Candida species. Mol Microbiol 13, 357-368.

Moore, M. M., Cooper, N. R., Tack, B. F. \& Nemerow, G. F. (1987). Molecular cloning of the cDNA encoding the Epstein-Barr virus C3d receptor (complement receptor type 2) of human B lymphocytes. Proc Natl Acad Sci USA 84, 9194-9198.

National Committee for Clinical Laboratory Standards. (1995). Reference method for broth dilution antifungal susceptibility testing of yeasts. Tentative standard. NCCLS document M27-T 15(10). Wayne PA: National Committee for Laboratory Standards.

Pfaller, M. A., Rhine-Chalberg, J., Redding, S. W., Smith, J., Farinacci, G., Fothergill, A. W. \& Rinaldi, M. G. (1994). Variations in fluconazole susceptibility and electrophoretic karyotype among oral isolates of Candida albicans from patients with AIDS and oral candidiasis. J Clin Microbiol 32, 59-64.

Philippsen, P., Stotz, A. \& Scherf, C. (1991). DNA of Saccharomyces cerevisiae. Methods Enzymol 194, 169-182.

Qin, S., Xie, A., Bonato, M. C. M. \& McLaughlin, C. S. (1990). Sequence analysis of the translational elongation factor 3 from Saccharomyces cerevisiae. J Biol Chem 265, 1903-1912.

Sambrook, J., Fritsch, E. F. \& Maniatis, T. (1989). Molecular Cloning: a Labarotory Manual, 2nd edn. Cold Spring Harbor, NY: Cold Spring Harbor Laboratory.

Sangeorzan, J. A., Bradley, S. F., He, X., Zarins, L. T., Ridenour, G. L., Tiballi, R. N. \& Kauffman, C. A. (1994). Epidemiology of oral candidiasis in HIV-infected patients: colonization, infection, treatment and emergence of fluconazole resistance. Am J Med 97, 339-346.

Sanger, F., Nicklen, S. \& Coulson, A. R. (1977). DNA sequencing with chain-terminating inhibitors. Proc Natl Acad Sci, USA 74, 5463-5467.

Sanglard, D., Kuchler, K., Ischer, F., Pagani, J. L., Monod, M. \& Bille, J. (1995). Mechanisms of resistance to azole antifungal agents in Candida albicans isolates from AIDS patients involve specific multidrug transporters. Antimicrob Agents Chemother 39, 2378-2386.

Sanglard, D., Ischer, F., Monod, M. \& Bille, J. (1996). Susceptibilities of Candida albicans multidrug transporter mutants to various antifungal agents and other metabolite inhibitors. Antimicrob Agents Chemother 40, 2300-2305.

Sanglard, D., Ischer, F., Monod, M. \& Bille, J. (1997). Cloning of Candida albicans genes conferring resistance to azole antifungal agents: characterization of $C D R 2$, a new multidrug $A B C$ transporter gene. Microbiology 143, 405-416.

Saxena, A. \& Calderone, R. (1990). Purification and characterization of the extracellular C3d-binding protein of Candida albicans. Infect Immun 56, 309-314.

Shepherd, M. G., Yin, C. Y., Ram, S. P. \& Sullivan, P. A. (1980). Germ tube induction in Candida albicans. Can J Microbiol 26, 21-26.

Sherman, F., Fink, G. R. \& Hicks, J. B. (1986). Methods in Yeast Genetics, Cold Spring Harbor, NY: Cold Spring Harbor Laboratory.

Silver, J. (1992). Inverse polymerase chain reaction. In PCR: $a$ Practical Approach, pp. 137-146. Edited by M. J. McPherson, P. Quirke \& G. R. Taylor. Oxford: Oxford University Press.

Titus, D. E. (1991). Promega Protocols and Applications Guide, 2nd edn. Madison, WI: Promega.

Vazquez de Aldana, C. R., Marton, M. J. \& Hinnebusch, A. J. (1995). GCN20, a novel ATP-binding cassette protein, and GCN1 reside in a complex that mediates activation of the eIF- $2 \alpha$ kinase GCN2 in amino acid-starved cells. EMBO J 14, 3184-3199.

White, T. (1997). Increased mRNA levels of ERG16, CDR1 and $M D R 1$ correlate with increases in azole resistance in Candida albicans isolates from a patient infected with human immunodeficiency virus. Antimicrob Agents Chemother 41, 1482-1487.

Wickes, B. L., Golin, E. J. \& Kwon-Chung, K.-J. (1991a). Chromosomal rearangement in Candida stellatoidea results in a positive effect on phenotype. Infect Immun 59, 1762-1771.

Wickes, B. L., Staudinger, J., Magee, B. B., Kwon-Chung, K.-J., Magee, P. T. \& Scherer, S. (1991b). Physical and genetic mapping of Candida albicans: several genes previously assigned to chromosome 1 map to chromosome $\mathrm{R}$, the rDNA-containing linkage group. Infect Immun 59, 2480-2484.

Ypma-Wong, M. F., Fonzi, W. A. \& Sypherd, P. S. (1992). Fungal specific translation factor 3 gene present in Pneumocystis carinii. Infect Immun 60, 4140-4145.

Received 27 January 1998; revised 27 March 1998; accepted 6 April 1998. 